OPEN ACCESS

Edited by:

Leonardo Alexandre Peyré-Tartaruga, Universidade Federal do Rio Grande

do Sul, Brazil

Reviewed by:

Lykke Sylow,

University of Copenhagen, Denmark Mildred Audrey Pointer,

North Carolina Central University,

United States

*Correspondence:

Zhemin Lin

Lzmin01@126.com

Xiquan Zhang

xqzhang@scau.edu.cn

${ }^{\dagger}$ These authors have contributed equally to this work.

Specialty section

This article was submitted to Integrative Physiology, a section of the journal

Frontiers in Physiology

Received: 08 February 2017

Accepted: 14 June 2017

Published: 29 June 2017

Citation:

Qiu F, Xie L, Ma J-e, Luo W, Zhang L,

Chao Z, Chen S, Nie Q, Lin Z and

Zhang X (2017) Lower Expression of SLC27A1 Enhances Intramuscular Fat

Deposition in Chicken via Down-Regulated Fatty Acid Oxidation Mediated by CPT1A

Front. Physiol. 8:449.

doi: 10.3389/fphys.2017.00449

\title{
Lower Expression of SLC27A1 Enhances Intramuscular Fat Deposition in Chicken via Down-Regulated Fatty Acid Oxidation Mediated by CPT1A
}

\begin{abstract}
Fengfang Qiu ${ }^{1,2 \dagger}$, Liang Xie ${ }^{3 \dagger}$, Jing-e Ma ${ }^{1}$, Wen Luo ${ }^{1}$, Li Zhang ${ }^{1}$, Zhe Chao ${ }^{3}$, Shaohao Chen ${ }^{1}$, Qinghua Nie ${ }^{1}$, Zhemin Lin $^{3 *}$ and Xiquan Zhang ${ }^{1 *}$
\end{abstract}

${ }^{1}$ Guangdong Provincial Key Lab of Agro-Animal Genomics and Molecular Breeding, and Key Lab of Chicken Genetics, Breeding and Reproduction, Ministry of Agriculture, College of Animal Science, South China Agricultural University, Guangzhou, China, ${ }^{2}$ School of Chemistry, Biology and Material Science, East China University of Technology, Nanchang, China, ${ }^{3}$ Department of Poultry Science, Institute of Animal Science and Veterinary, Hainan Academy of Agricultural Sciences, Haikou, China

Intramuscular fat (IMF) is recognized as the predominant factor affecting meat quality due to its positive correlation with tenderness, juiciness, and flavor. Chicken IMF deposition depends on the balance among lipid synthesis, transport, uptake, and subsequent metabolism, involving a lot of genes and pathways, however, its precise molecular mechanisms remain poorly understood. In the present study, the breast muscle tissue of female Wenchang chickens (WC) (higher IMF content, 1.24 in D120 and 1.62 in D180) and female White Recessive Rock chickens (WRR; lower IMF content, 0.53 in D120 and 0.90 in D180) were subjected to RNA-sequencing (RNA-seq) analysis. Results showed that many genes related to lipid catabolism, such as SLC27A1, LPL, $A B C A 1$, and CPT1A were down-regulated in WC chickens, and these genes were involved in the PPAR signaling pathway and formed an IPA ${ }^{\circledR}$ network related to lipid metabolism. Furthermore, SLC27A1 was more down-regulated in WRR.D180.B than in WRR.D120.B. Decreased cellular triglyceride (TG) and up-regulated CPT1A were observed in the SLC27A1 overexpression QM-7 cells, and increased cellular triglyceride (TG) and down-regulated CPT1A were observed in the SLC27A1 knockdown QM-7 cells. These results suggest that lower lipid catabolism exists in WC chickens but not in WRR chickens, and lower expression of SLC27A1 facilitate IMF deposition in chicken via down-regulated fatty acid oxidation mediated by CPT1A. These findings indicate that reduced lipid catabolism, rather than increased lipid anabolism, contributes to chicken IMF deposition.

Keywords: SLC27A1, Intramuscular fat, RNA-sequencing, lipid catabolism, fatty acid oxidation, CPT1A

\section{INTRODUCTION}

Meat products are important components of human food. In the last several decades, great progress has been made in meat quantity by genetic selection for growth rate and meat yield, however, higher growth rate also induced larger fiber diameters, higher proportion glycolytic fibers, and lower intramuscular fat, which seriously deteriorated the quality of meat 
(Dransfield and Sosnicki, 1999; Du et al., 2010; Petracci and Cavani, 2012). It is an ongoing challenge to improve meat quality meanwhile maintain growth rate.

Meat quality is affected by many factors, among which intramuscular fat (IMF) is predominant. IMF refers to the amount of fat within muscles, including those localized in the epimysium, perimysium, and endomysium (Fernandez et al., 1999a). Unlike adipose tissue, in which the major lipid category is triglyceride (TG, >90\%), a significant proportion of IMF is phospholipid. IMF has a plentiful polyunsaturated fatty acid (PUFA) composition and content, such as linoleic acid (18:2n6), a-linolenic acid (18:3n-3) and arachidonic acid (20:4n-6; Wood et al., 2008). These PUFAs are readily oxidized by heating, producing volatile components such as 2,4-Decadienal which improves the flavor of meat (Calkins and Hodgen, 2007). Lots of studies have shown that IMF content was positively correlated with flavor, juiciness, and tenderness (Fernandez et al., 1999a,b; Chartrin et al., 2006; Gao and Zhao, 2009; Cannata et al., 2010; Hocquette et al., 2010; Madeira et al., 2013).

Different from mammals, in which de novo synthesis of fatty acids mainly occurs in adipocytes, the chicken synthesize its fatty acids predominantly in the liver (Leveille, 1969; Vernon et al., 1999), similar to fish (Rollin et al., 2003), and then exported to other tissues including both muscle and adipose tissue by the peripheral vascular system. Therefore, chicken IMF accumulation is dependent on the transport and uptake of blood lipids as well as lipogenesis subsequently in muscle rather than de novo fatty acids synthesis (Griffin et al., 1987). Previous studies have identified about 20 quantitative trait loci (QTL) related to chicken IMF, which are mainly located on chromosomes 1, 2, 5, 23 (Jennen et al., 2005; D’Andre et al., 2010; Ye et al., 2010; Jia et al., 2012; Liu et al., 2013; Nassar et al., 2013; Sun et al., 2013; Zhang T. et al., 2015). Otherwise, a large number of genes including GPAT1, ACC, CD36, AGPAT1, and DGAT2 (Jeong et al., 2012), FABP (Ye et al., 2010; Serao et al., 2011), LPL (Zhang X. D. et al., 2015), DGAT1 (Li et al., 2013) were recognized as candidate genes for IMF, but their molecular mechanisms affecting IMF are still unclear. Obviously, the mechanism underlying chicken IMF deposition is very complicated, involving a lot of genes and metabolic pathways (Figure 1).

Although, previous studies have analyzed the transcriptome of chicken breast muscle (Cui et al., 2012) and liver (Bourneuf et al., 2006) utilizing microarrays, and identified some potential

\footnotetext{
Abbreviations: ABCA1, ATP-Binding Cassette Transporter A1; ACC, AcetylCOA carboxylase; ACSL1, Long chain Acyl-CoA synthetase 1; AGPAT, 1Acylglycerol-3-phosphate O-acyltransferase; CETP, Cholesteryl ester transfer protein; CPT1A, Carnitine palmitoyl transferase I A; DEG, differentially expressed genes; DGAT, Diacylglycerol; FABP, Fatty acid binding protein; FABPpm, Plasm membrane fatty acid binding protein; FAT/CD36, Fatty acid translocase; FBXO32, F-Box Protein 32; FDR, false discovery rate; GAPDH, Glyceraldehyde3-phosphate dehydrogenase; GO, Gene ontology; GPAT1, Glycerol-3-phosphate acyltransferases 1; IMF, Intramuscular fat; IPA, Ingenuity Pathway Analysis; KEGG, Kyoto Encyclopedia of Genes and Genomes; LPL, Lipoprotein lipase; MUSTN1, Musculoskeletal, Embryonic Nuclear Protein 1; PPP3CA, Protein Phosphatase 3 Catalytic Subunit Alpha; QM-7 cells, Quail myoblast; qRT-PCR, quantitative real-time PCR; RNA-seq, RNA-sequencing; SLC27A1, Fatty acid transporter 1 (FATP1); SLC27A4, Fatty acid transporter 4 (FATP4).
}

candidate genes and pathways that influence chicken breast muscle IMF deposition, no further validation has been performed. Therefore, the precise molecular mechanisms underlying chicken IMF deposition have not been fully elucidated so far. In the present study, female breast muscle of Wenchang chicken (WC, Chinese native breed, high IMF content) and Recessive White Rock chicken (WRR, imported and fast-growing breed, low IMF content) were subjected to RNA-sequencing (RNA-seq) analyses. Results showed that chicken IMF deposition is attributable to some key genes and pathways related to lipid catabolism rather than lipid anabolism, and the higher IMF deposition might resulted from lower lipid oxidation.

\section{MATERIALS AND METHODS}

\section{Ethics Statement}

All animal procedures were authorized by the Animal Care Committee of South China Agricultural University (Guangzhou, China). Animals involved in the present study were sacrificed as necessary to ameliorate their suffering.

\section{Animals and Sample Collection}

In the present study, WC chickens were collected from Longquan Wenchang Chicken Industrial co., LTD (Wenchang, Hainan, China), and WRR chickens were collected from Guangdong Wen's Food Group, LTD (Xinxing, Guangdong, China). Birds were raised up to $120 \mathrm{~d}$ of age (D120) or $180 \mathrm{~d}$ of age (D180), six female birds of similar weight from each breed per age were sacrificed for muscle sample collection. The center of right breast muscle (B) was excised, divided into three parts for RNA-seq, qRT-PCR, and Oil Red O staining respectively, snap-frozen in liquid nitrogen immediately and stored long-term at $-80^{\circ} \mathrm{C}$. The whole left breast muscle was excised for IMF content measurement and stored at $-30^{\circ} \mathrm{C}$.

\section{Oil Red O Staining and IMF Content Measurement}

Frozen tissues were sectioned using a Leica Kryostat (Leica CM3050S, Leica instrument $\mathrm{GmbH}$, Germany), fixed $30 \mathrm{~min}$ with $10 \%$ paraformaldehyde, and incubated $15 \mathrm{~min}$ at room temperature with Oil Red $\mathrm{O}$, then visualized with light microscopy.

IMF contents were measured in a Soxhlet apparatus (Soxtherm, German), according to the description elsewhere (Zerehdaran et al., 2004; Cui et al., 2012). The data are represented as percentages of the wet weight of the muscle.

\section{Total RNA Extraction and cDNA Synthesis}

Total RNA was extracted from muscle samples or cells with RNAiso reagent (Takara, Otsu, Japan) and treated with DNase I (Takara). The integrity and concentration of RNA were assessed by $1.2 \%$ denatured gel electrophoresis and NanoDrop 2000c instrument (Thermo, Waltham, MA, USA). cDNA synthesis was carried out using a PrimeScript RT reagent Kit (Perfect Real Time) (Takara) according to the manufacturer's instruction. 


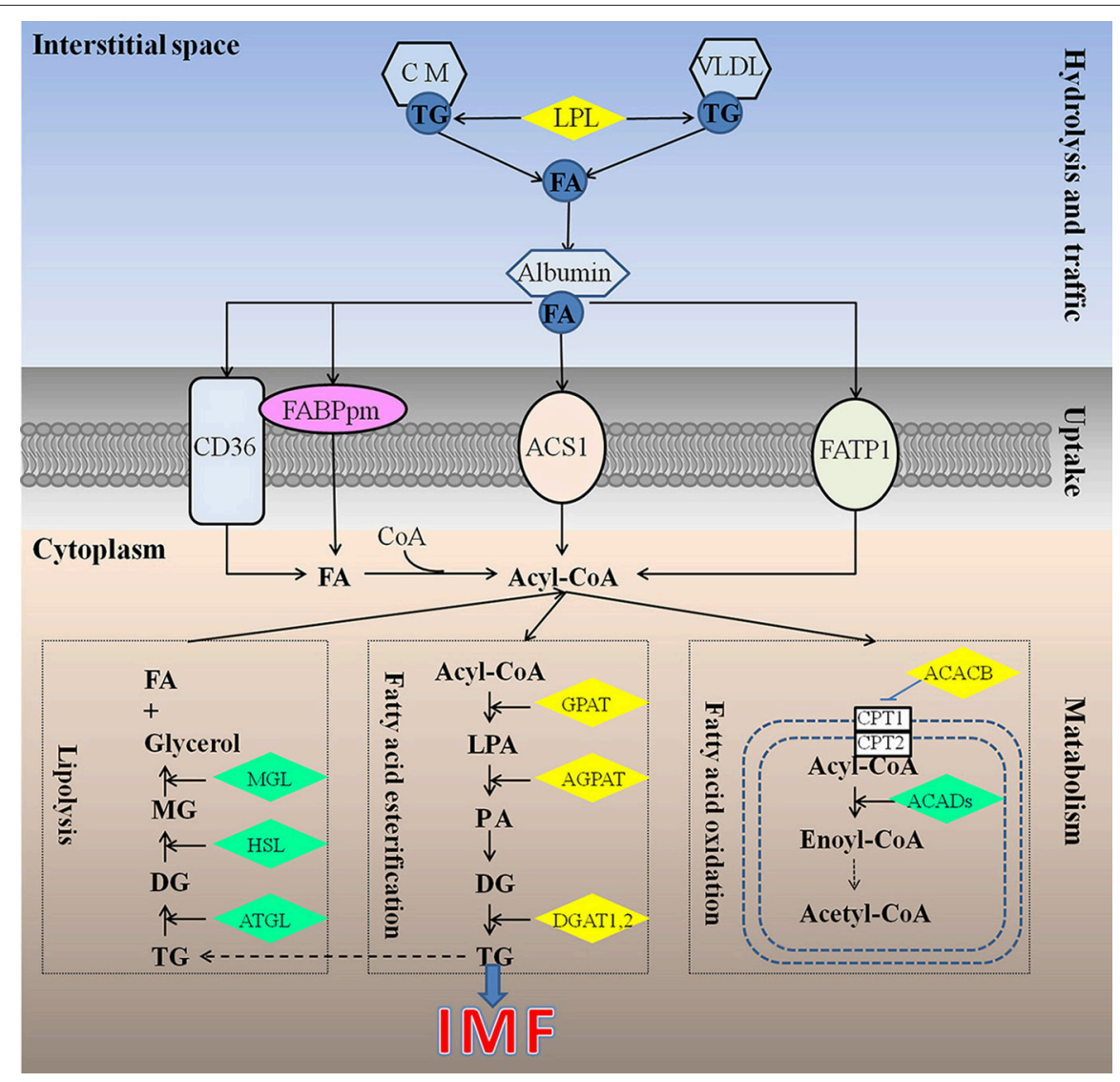

FIGURE 1 | Underlying mechanism for IMF deposition in chickens. Hydrolysis and traffic: Both endogenous lipids synthesized by liver and exogenous lipids uptake from diet were hydrolyzed by LPL (Griffin et al., 1987), to produce FA. FA bound with albumin immediately, and be transported to muscles or other tissues (Schwenk et al., 2010). Uptake: it is generally recognized that fatty acids cross the cell membrane via a protein-mediated mechanism rather than by passive diffusion, and 4 proteins be identified responsible for fatty acids uptake, such as FABPpm, CD36, FATP1, and ACS1, could act, either alone or together, to enhance the fatty acid influx events (Glatz et al., 2010). Metabolism: IMF accumulation depends on the balance among fatty acids esterification, lipolysis, and oxidation (Jeong et al., 2012). ACACB, acetyl-CoA carboxylase beta; ACADs, acyl-CoA dehydrogenases; ACS1, Acyl-CoA synthetase; AGPAT, 1-acylglycerol-3-phosphate O-acyltransferase; ATGL, triglyceride lipase; CD36, Fatty acid translocase; CM, chylomicron; CPT1, carnitine palmitoyltransferase 1; CPT2, carnitine palmitoyltransferase 2; DG, diacylglycerol; DGAT, diacylglycerol acyltransferase; FA, fatty acid; FABPpm, Plasm membrane Fatty acid binding protein; FATP1, Fatty acid transporter 1; GPAT, glycerol-3-phosphate acyltransferases; HSL, hormone sensitive lipase; LPA, Iysophosphatidic acid; LPL, lipoprotein lipase; MG, monoacylglycerol; MGL, monoacylglycerol lipase; PA, phosphatidic acid; TG, triglyceride; VLDL, very low density lipoprotein.

\section{RNA-Seq Analyses}

For each breed at each age, two birds were selected randomly from the total of six birds for RNA-seq respectively. So eight muscle samples in total were subjected to RNA-seq analysis, four WC chicken samples including WC.D120.B1, WC.D120.B-3, WC.D180.B-2, and WC.D180.B-3, and four WRR chicken samples including WRR.D120.B-4, WRR.D120.B6, WRR.D180.B-2, and WRR.D180.B-5.

After the total RNA extraction and DNase I treatment, magnetic beads with Oligo (dT) were used for mRNA enrichment. The enriched mRNA was fragmented, and used as templates for synthesizing cDNA. Short cDNA fragments were purified, end-repaired, tailed with single nucleotide adenine, and then connected with adapters. With agarose gel electrophoresis, suitable fragments were amplified with PCR. Subsequently the sample library was assessed with an Agilent 2100 Bioanaylzer and ABI StepOnePlus Real-Time PCR System for quantity and quality. Finally, the library was sequenced using Illumina HiSeq $^{\text {TM }} 2000$ (BGI, China).

Primary sequencing data that produced by Illumina HiSeq ${ }^{\mathrm{TM}}$ 2000 , called raw reads, were subjected to quality control (QC) to determine whether a resequencing step was needed. After QC, raw reads were filtered, and clean reads were aligned to reference sequences with SOAPaligner/SOAP2 (Li et al., 2009). Then the alignment data were utilized to calculate distribution and coverage of reads on reference genes. Next, we proceeded with gene expression analysis, which included gene expression level and differential expression gene (DEG). Furthermore, we performed Gene Ontology (GO) enrichment analysis (Ashburner et al., 2000; Young et al., 2010), KEGG (Kyoto Encyclopedia of Genes and Genomes, http://www. genome.jp/kegg/) Pathway enrichment analysis (Altermann and Klaenhammer, 2005; Kanehisa et al., 2008) and Ingenuity ${ }^{\circledR}$ Pathway Analysis (IPA ${ }^{\circledR}$, http://www.ingenuity.com/) of DEGs. 


\section{Quantitative RT-PCR Analysis}

The primers for qRT-PCR were designed by Primer premier 5 software. The forward $(\mathrm{F})$ and reverse (R) primer of each gene were derived from different exons, and the size of each PCR product was about $150 \sim 250 \mathrm{bp}$. qRT-PCR was carried out in a Bio-rad CFX96 Real-Time Detection system (Biorad, Hercules, CA, USA) employing KAPA SYBR FAST q-PCR Kit (KAPA Biosystems, Wobrun, MA, USA) according to the manufacturer's instruction. The $2^{-(\Delta \Delta \mathrm{Ct})}$ formula was used to quantify the relative gene expression with $G A P D H$ as a reference gene (Vandesompele et al., 2002).

\section{Plasmids Construction and siRNA Oligonucleotides Synthesis}

pcDNA-3.1(+)-SLC27A1 expression vector. The SLC27A1 coding sequence containing 1941 base pairs was amplified from chicken breast muscle cDNA, and the specific primers as follows: $5^{\prime}$-cttaagcttatgcagcccgtgggggtgt- $3^{\prime}$ and $5^{\prime}$-gcagaattctcataaggcgactttcccggagca- $3^{\prime}$. The PCR product was cloned into the pcDNA-3.1(+) vector (Promega, Madison, WI, USA) using restriction enzymes EcoRI and HindIII.

SiRNA oligonucleotides and negative control (NC) for gene interference were purchased from GenePharma (GenePharma, Suzhou, China).

\section{Cell Culture}

The QM-7 myoblasts were incubated in a humidified atmosphere containing 5\% $\mathrm{CO}_{2}$ in M199 medium containing $10 \%$ fetal bovine serum (FBS), 10\% tryptose phosphate broth, $0.1 \%$ penicillin, and $0.1 \%$ streptomycin (growth medium). Cells were incubated in this growth medium for $48 \mathrm{~h}$, the density reached to $80 \sim 90 \%$. Then the cells were induced to differentiate by lowering FBS concentration to $1 \%$ (differentiation medium) for another $48 \mathrm{~h}$, reaching $80 \sim 90 \%$ preconfluent. Then the preconfluent myoblasts were used for subsequent transfection experiments.

\section{Transfection Experiment}

The plasmids $p c D N A 3.1(+)-S L C 27 A 1$ and $p c D N A 3.1(+)-E G F P$, or gga-1220 (siRNA) and NC, were transfected in QM-7 cells which incubated in 6-well plates using Lipofectamine ${ }^{\circledR} 3000$ reagent (Invitrogen) following the manufacturer's guidelines. After that, cells were incubated and differentiated for $48 \mathrm{~h}$, and reaching $80 \sim 90 \%$ confluent, then used for subsequent experiments.

\section{Measurement of Cellular TG and FFA}

Cells pretreated as described above were incubated further for $16 \mathrm{~h}$ at $37^{\circ} \mathrm{C}$ in serum free M199 medium containing $0.30 \mathrm{mM}$ palmitate (Sigma, USA) bound to $1 \%$ bovine serum albumin (BSA, Sigma, USA) and $0.05 \mathrm{mM} \mathrm{L-carnitine} \mathrm{(Sigma,} \mathrm{USA).} \mathrm{After}$ that, the cells were washed, collected and diluted with phosphatebuffered saline (PBS, pH 7.2-7.4). Cellular TG and free fatty acid (FFA) concentrations were measured using Chicken Triglyceride (TG) and FFA ELISA Kits (Jiyinmei Biological Technology Co., LTD, Wuhan, China), according to the manufacturer's guidelines.

\section{Statistical Analyses}

Data are presented as means \pm S.E.M based on at least three replicates for each treatment. A one-way ANOVA was used to determine statistical significance, where $P<0.05$ was considered significant differences.

\section{RESULTS}

\section{IMF Content of WC Chicken and WRR Chicken}

To visualize the difference of IMF deposition between breeds and within breeds, breast muscle samples were subjected to Oil Red $\mathrm{O}$ staining. Between the two breeds, the density and size of lipids in WC.D120.B (Figure 2A) and WC.D180.B (Figure 2B) were larger than those of in WRR.D120.B (Figure 2C) and WRR.D180.B (Figure 2D). Within breed, the density and size of lipids in D180 muscles were larger than that of in D120 muscles. To further quantify the difference of IMF deposition in chickens, we measured the IMF content of breast muscles using Soxhlet apparatus and the data were showed in Table 1. IMF content of WC muscles were significantly higher than that of WRR muscles $(P<0.01), 1.24$ vs. 0.53 in D120 and 1.62 vs. 0.90 in D180, respectively. Within breed, the IMF content in D180 muscles were significantly higher than that in D120 muscles $(P<0.01)$.

\section{Transcriptome Assembly and Statistics of RNA-Seq}

To identify the underlying molecular mechanism responsible for chicken IMF deposition, the transcriptome of breast muscle of WC chicken and WRR chicken at different ages were analyzed with RNA-seq. Two birds per breed of each age were selected to produce cDNA libraries for RNA-seq separately. The clean reads of each sample were over 20 million, the expressed genes ranged from 16,202 to 17,838 , and a little higher in WRR samples than in WC samples (Table 2).

\section{Differentially Expressed Genes (DEGs)}

Generally, false discovery rate (FDR) $<0.05$ and twofold difference together was regarded as differentially expressed. In the present study, there were 525, 161, 23, 87 DEGs detected in the comparisons of WRR.D120.B-VSWC.D120.B， WRR.D180.B-VS-WC.D180.B，WC.D120.B-VSWC.D180.B, and WRR.D120.B-VS-WRR.D180.B, respectively (Figure 3).

Of the shared DEGs among four comparisons, FBXO32 was the most common gene shared by all four comparisons, while PPP3CA was the common gene in WRR.D120.B-VSWC.D120.B, WC.D120.B-VS-WC.D180.B, and WRR.D120.BVS-WRR.D180.B. In addition, a total of 46 DEGs were shared by WRR.D120.B-VS-WC.D120.B and WRR.D180.BVS-WC.D180.B, of which 12 were up-regulated in WC chicken, the rest were up-regulated in WRR chicken. These DEGs may be correlated with the different development properties of breast muscle between breeds. Otherwise, MUSTN1 and PPP3CA were the other two common genes 

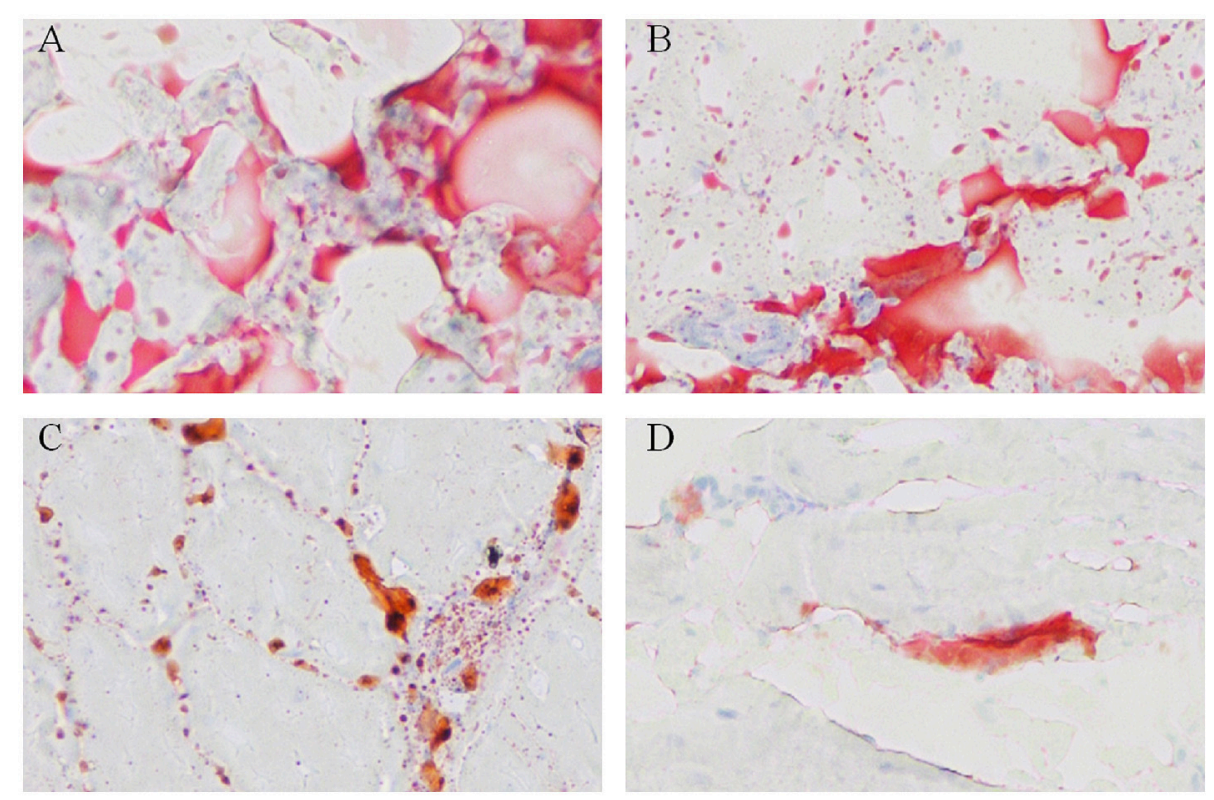

FIGURE 2 | Oil Red O staining for neutral lipids in breast muscle of WC and WRR chickens (200X). Breast muscle samples were paraformaldehyde fixed and incubated with Oil Red O and visualized by light microscopy. (A) Lipids in WC.D180.B. (B) Lipids in WC.D120.B. (C) Lipids in WRR.D180.B. (D) Lipids in WRR.D120.B. The picture presented is representative of three independent experiments.

TABLE 1 | IMF content of WC and WRR (WET, \%).

\begin{tabular}{|c|c|c|}
\hline $\begin{array}{ll}\text { ages } & \text { Breeds }\end{array}$ & WC & WRR \\
\hline D120 & $1.24 \pm 0.09^{A}$ & $0.53 \pm 0.11^{B}$ \\
\hline D180 & $1.62 \pm 0.14^{A^{\star}}$ & $0.90 \pm 0.05^{B^{\star \star}}$ \\
\hline
\end{tabular}

Data are presented as means \pm S.E.M $(n=6)$, different capital superscripts in each row indicate extremely significant differences $(P<0.01)$, * in each column means significant differences $(P<0.05)$, ${ }^{* *}$ in each column means extremely significant differences $(P<$ 0.01). WC, Wenchang chicken; WRR, White Recessive Rock chicken.

TABLE 2 | Statistics of RNA-seq data.

\begin{tabular}{lcccc}
\hline Samples & Clean reads & $\begin{array}{c}\text { Genome } \\
\text { map rate (\%) }\end{array}$ & $\begin{array}{c}\text { Gene map } \\
\text { rate (\%) }\end{array}$ & $\begin{array}{c}\text { Expressed } \\
\text { genes }\end{array}$ \\
\hline WC.D120.B-1 & 20566818 & 63.09 & 64.11 & 16202 \\
WC.D120.B-3 & 21126204 & 63.85 & 64.86 & 16475 \\
WC.D180.B-2 & 23644072 & 65.81 & 60.99 & 16821 \\
WC.D180.B-3 & 24164920 & 64.18 & 67.30 & 17136 \\
WRR.D120.B-4 & 25413150 & 62.87 & 64.02 & 17349 \\
WRR.D120.B-6 & 25407212 & 64.26 & 64.48 & 17340 \\
WRR.D180.B-2 & 23458948 & 66.03 & 63.38 & 17240 \\
WRR.D180.B-5 & 23346692 & 65.54 & 66.86 & 17838
\end{tabular}

WC, Wenchang chicken; WRR, White Recessive Rock chicken; B, breast muscle.

shared by WC.D120.B-VS-WC.D180.B and WRR.D120.BVS-WRR.D180.B, which might be involved in regulating the temporal characteristics of breast muscle development. The shared DEGs were presented in Supplementary Table 1.

\section{Quantitative Real-Time PCR Verification of DEGs}

To verify the gene expression pattern of DEGs detected by RNAseq, a total of 20 genes were selected randomly to perform quantitative real-time PCR experiments and the primers were listed in Supplementary Table 2. The gene expression pattern of quantitative real-time PCR were generally accordant with that of RNA-seq, although different in fold changes (Figure 4), which indicated that our RNA-seq data were reliable.

\section{GO Terms for DEGs}

GO-term analysis was used to investigate the function of DEGs. In the present study, the enriched GO-terms (Corrected $P<0.05)$ in the ontology classification "biological process" were represented in Figure 5. Between breeds, the enriched biological process mainly including multicellular organismal process, response to stimulus, biological regulation, regulation of biological process, regulation of cellular process, cellular developmental process, tissue development. The enriched biological process within WC chicken mainly focused on ion transport (Figure 5), no biological process was enriched within WRR chicken.

\section{Key DEGs Associated with Chicken IMF Deposition}

Based on GO function annotation, DEGs related to lipid metabolism would be attributable to chicken IMF deposition. Total of 33 (between breeds) and seven (between ages) DEGs were associated with IMF deposition (Supplementary Table 3). There were 24 DEGs down-regulated in WC chicken, including 

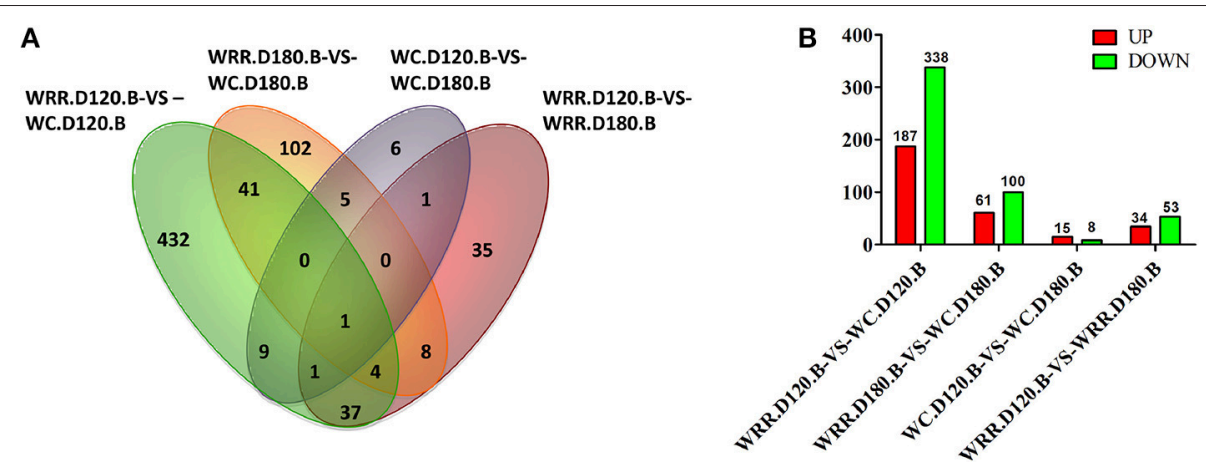

FIGURE 3 | Differentially expressed genes among four comparisons. (A) Differentially expressed genes that are unique or shared among four comparisons. (B) Differentially expressed genes that are up-regulated expression (red) or down-regulated expression (green) in the latter of each contrast. WC, Wenchang chicken; WRR, White Recessive Rock chicken; B, breast muscle.

A

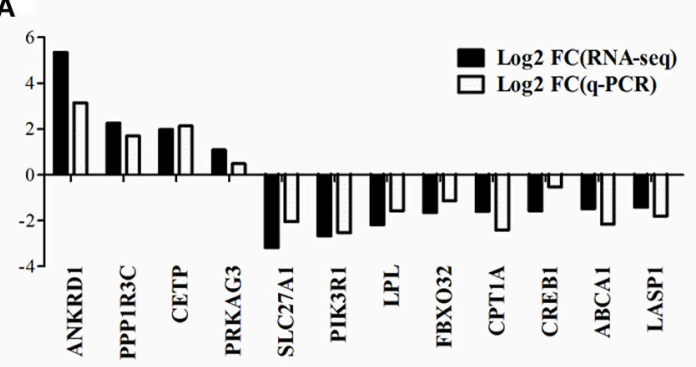

C

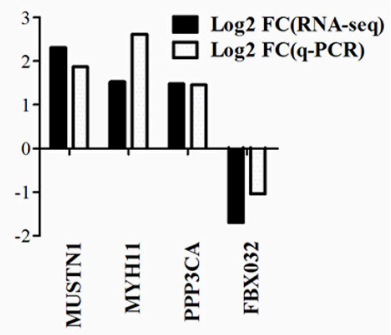

B

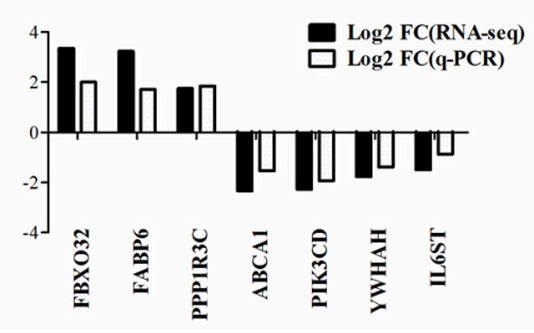

D

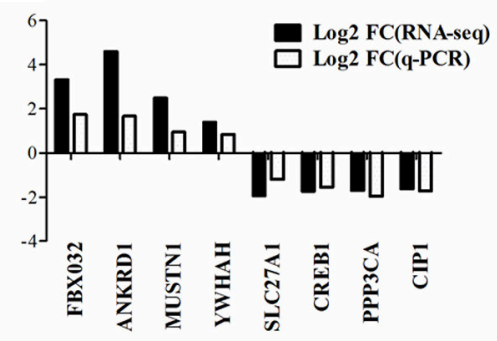

FIGURE 4 | Quantitative real-time PCR verification of DEGs detected from RNA-seq. The data presented are representative of three independent experiments performed at least three biological replicates; mean \pm S.E.M. (A) DEGs in WRR.D120.B-VS-WC.D120.B. (B) DEGs in WRR.D180.B-VS-WC.D180.B. (C) DEGs in WC.D120.B-VS-WC.D180.B. (D) DEGs in WRR.D120.B-VS- WRR.D180.B.

several well-known candidate genes for lipid metabolism, such as ABCA1 (Santamarina-Fojo et al., 2001), ACACB (Xu et al., 2014), CPT1A (Akkaoui et al., 2009), LPL (Claire et al., 2013; Zhang X. D. et al., 2015), and SLC27A1 (Sebastian et al., 2009; Guitart et al., 2014), of which SLC27A1 was also more down-regulated in WRR.D180.B than in WRR.D120.B. In other words, SLC27A1 were generally lower expressed in the higher IMF muscles.

\section{Pathways for DEGs}

In vivo, lots of genes execute their biological function concertedly, and pathway enrichment analysis can reveal the main biochemical metabolism process and signal transduction pathways in which DEGs are involved. In the present study, pathways significantly enriched with DEGs were assessed by a hypergeometric test using $\mathrm{R}$ packages $(P<0.05$, FDR adjusted). As presented in Figure 6, there were 14 (in D120) and 13 (in D180) pathways identified in DEGs between breeds, with eight being shared by two ages which included MAPK signaling, TGF-beta, cytokine-cytokine receptor interaction, focal adhesion, regulation of actin cytoskeleton, arrhythmogenic right ventricular cardiomyopathy (ARVC), cardiac muscle contraction, hypertrophic cardiomyopathy (HCM). Within breeds, between different ages, DEGs in WC chicken were enriched in MAPK signaling and regulation of actin cytoskeleton, while DEGs in WRR chicken were enriched in VEGF signaling and fat digestion and absorption (Figure 6). Similar results were obtained by previous study on Beijing-you chickens and Arbor Acres chickens using Agilent cDNA microarray (Cui et al., 2012). 


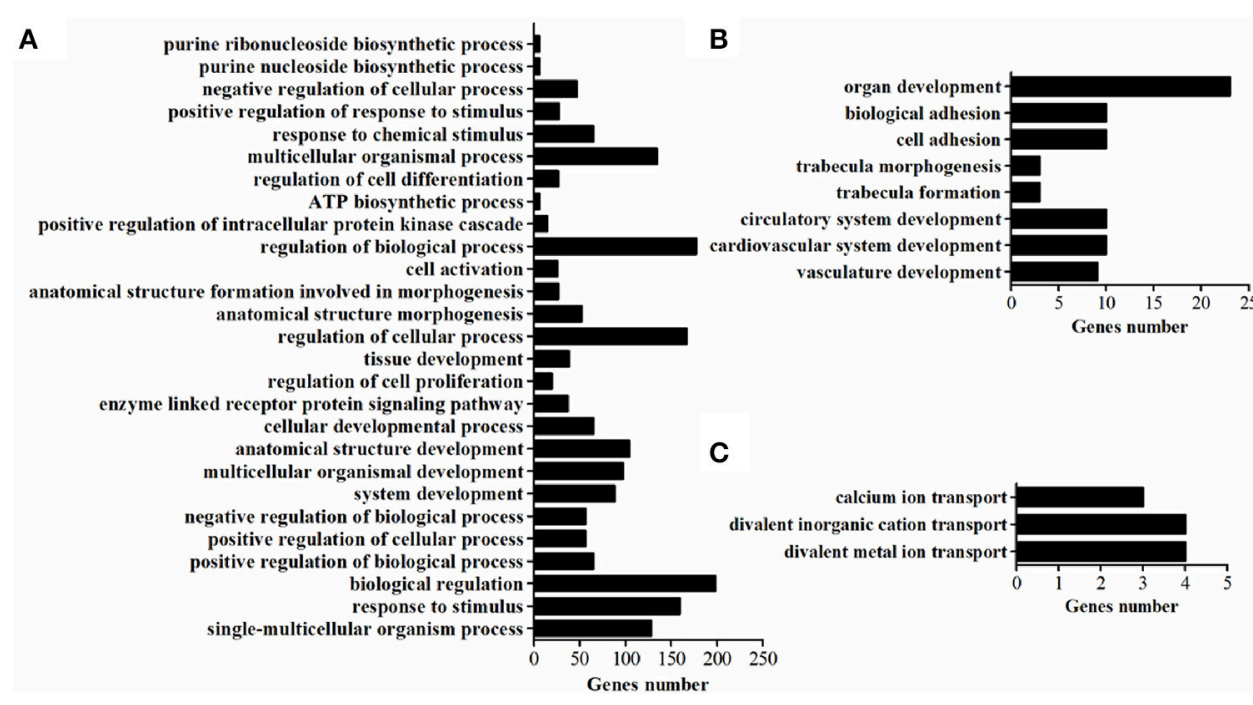

FIGURE 5 | The enriched biological processes of DEGs. (A) Biological processes enriched in DEGs in WRR.D120.B-VS-WC.D120.B. (B) Biological processes enriched in DEGs in WRR.D180.B-VS- WC.D180.B. (C) Biological processes enriched in DEGs in WC.D120.B-VS-WC.D180.B.

These results indicate that not only the pathways related to lipid metabolism (MAPK signaling; Kokta et al., 2004; Du et al., 2010), but also those involved in cell-links [cytokine-cytokine receptor interaction (Ozaki and Leonard, 2002), focal adhesion (Petit and Thiery, 2000), regulation of actin cytoskeleton (Pollard, 2003)] and cell cycle (TGF-beta; Shi and Massague, 2003) could dedicate to the IMF deposition, for their crucial role in maintaining the morphology of tissue and cell growth and proliferation. In addition, key DEGs related to lipid metabolism include CPT1A, CETP, LPL, and SLC27A1, all being involved in PPAR signaling pathway (Figure 7B), although it did not reach up to statistical significance $(P>0.05)$.

\section{Gene Networks for DEGs}

IPA ${ }^{\circledR}$ was performed to investigate genes affecting lipid metabolism between breeds. A total of 16 networks were identified in WRR.D120.B-VS-WC.D120.B (Supplementary Table 4) to be associated with post-translational modification, organismal injury and abnormalities, cell-to-cell signaling and interaction, energy production, cancer and lipid metabolism. The DEGs ABCA1, CPT1A, LPL, and SLC27A1, which were down-regulated in WC.D120.B and involved in PPAR signaling pathway (Figure 7B), acted as important node gene and interacted in the network of lipid metabolism, molecular transport, small molecule biochemistry (Figure 7A). CETP was another important node gene in this network, but up-regulated in WC.D120.B.

In WRR.D180.B-VS-WC.D180.B, five networks were identified (Supplementary Table 4) and they were mainly related to connective tissue development and function, cancer, organismal injury and abnormalities, nerve system development and function, dermatological diseases and conditions.

\section{Proposed Network for SLC27A1 to Regulate Chicken IMF Deposition}

Based on the above results and previous study, a network for SLC27A1 to regulate chicken IMF deposition was proposed (Figure 7C). In this proposed network, SLC27A1 might regulate LPL (Auwerx et al., 1996), or CPT1A (Mascaro et al., 1998; Song et al., 2010), or CETP (Li and Chiang, 2009), or ABCA1 (Chinetti et al., 2001), respectively or together via PPARs, and consequently regulate the lipid metabolism of WC chickens.

\section{SLC27A1 Overexpression Decreased Cellular TG and Increased CPT1A mRNA}

To further verify the role of SLC27A1 in lipid metabolism and its proposed molecular mechanism (Figure 7C), we overexpressed SLC27A1 in QM-7 cells. The primers for quantitative real-time PCR were presented in Supplementary Table 5.

Overexpression was achieved by transfection of QM-7 cells with pcDNA3.1(+)-SLC27A1 containing chicken full-length SLC27A1 cDNA. SLC27A1 mRNA levels increased over 34-fold in pcDNA3.1(+)-SLC27A1-transfected cells compared with control pcDNA3.1(+)-EGFP-transfected cells (Figure 8A). To assess the function of the overexpressed SLC27A1 in lipid metabolism, we measured the incorporation of palmitate into TG in QM-7 cells. Overexpressed SLC27A1 resulted in extremely significant decreases of cellular TG concentration $(2.32 \pm 0.23 \mathrm{~mm} / \mathrm{L}$ vs. 3.52 $\pm 0.12 \mathrm{~mm} / \mathrm{L}, P<0.01$, Figure 8B), and significant decreases of cellular FFA concentration $(335.35 \pm 12.13 \mu \mathrm{m} / \mathrm{L}$ vs. $355.94 \pm$ 6.32, $P<0.05$, Figure 8C), compared with control cells.

To investigate whether synergy or compensation effect exists among different fatty acid transporters, we evaluated SLC27A4, ACSL1, FABPpm/GOT2, FAT/CD36 mRNA levels in pcDNA3.1(+)-SLC27A1-transfected cells compared with control pcDNA3.1(+)-EGFP- transfected cells by quantitative real-time 

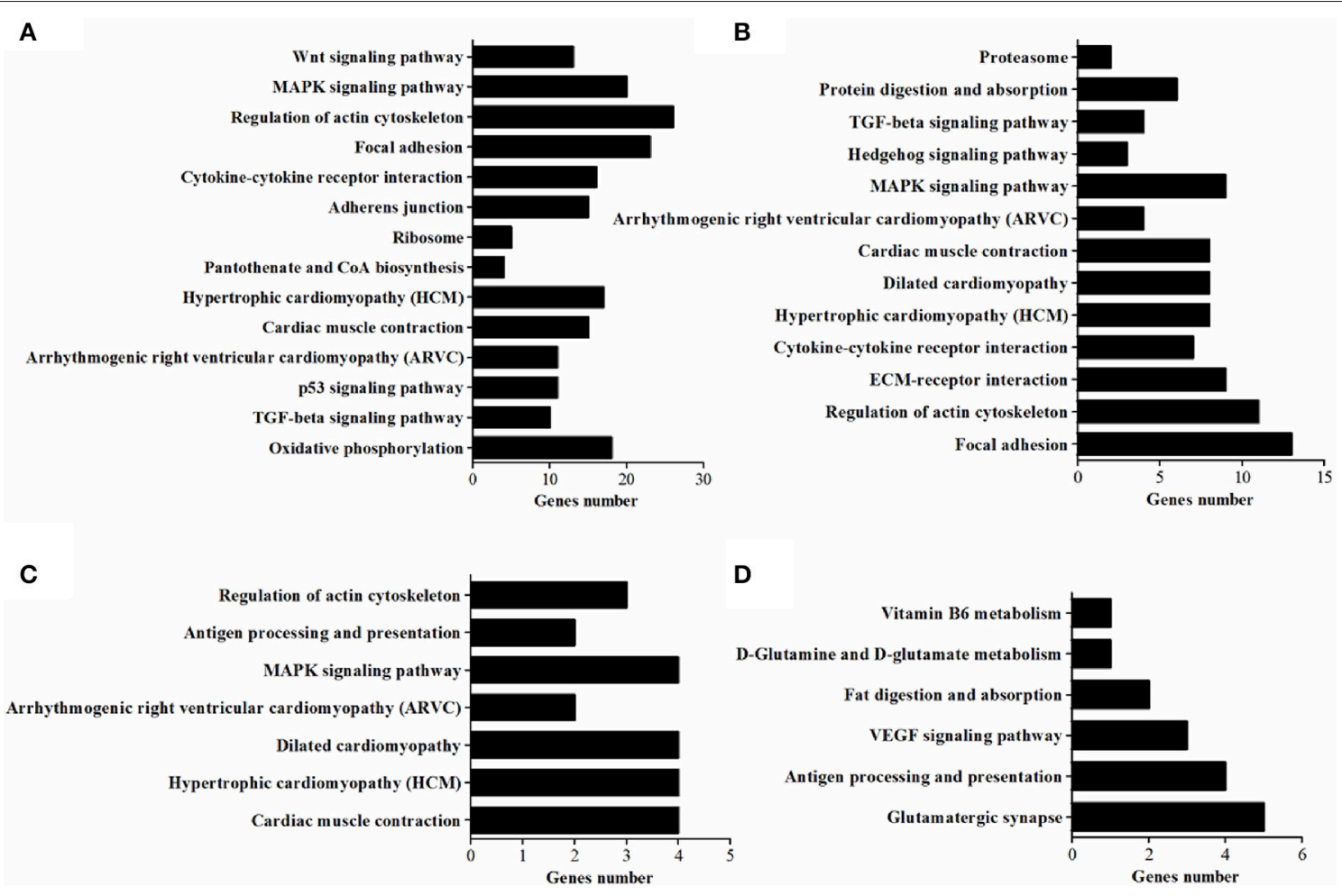

FIGURE 6 | The enriched KEGG pathways of DEGs. (A) Pathways enriched in DEGs in WRR.D120.B- VS-WC.D120.B. (B) Pathways enriched in DEGs in WRR.D180.B-VS- WC.D180.B. (C) Pathways enriched in DEGs in WC.D120.B-VS-WC.D180.B. (D) Pathways enriched in DEGs in WRR.D120.B-VS-WRR.D180.B.

PCR (Figure 8D). SLC27A1 overexpression resulted in the upregulated for SLC27A4 $(P<0.05)$, and no change was observed for ACSL1, GOT2, and CD36.

To investigate the molecular mechanism and biological pathway for SLC27A1 affecting IMF deposition, we assessed the mRNA levels of PPARs and DEGs involved in PPAR signaling pathway in pcDNA3.1(+)-SLC27A1-transfected cells compared with control $p c D N A 3.1(+)$-EGFP-transfected cells by quantitative real-time PCR (Figure 8E). Overexpressed SLC27A1 resulted in the up-regulated for and $C P T 1 A(P<0.05)$, while no changes were observed for other genes.

\section{SLC27A1 Knockdown Increased Cellular TG and Decreased CPT1A mRNA}

SLC27A1 knockdown was accomplished by RNA interference to further assess the function of SLC27A1. SiRNA SLC27A1-1220 for SLC27A1 and NC for GAPDH were transfected into QM-7 cells respectively. SLC27A1 mRNA levels decreased nearly to $50 \%$ in SLC27A1-1220-transfected cells compared with control NCtransfected cells (Figure 9A). To assess the effect of the SLC27A1 knockdown in lipid metabolism, we measured the incorporation of palmitate into TG in QM-7 cells. SLC27A1 knockdown resulted in significant increases of cellular TG concentration (4.04 \pm 0.10 and $3.55 \pm 0.17 \mathrm{~mm} / \mathrm{L}, P<0.05$, Figure 9B), and significant decreases of cellular FFA concentration (394.27 \pm $18.36 \mu \mathrm{m} / \mathrm{L}$ and $465.01 \pm 18.21, P<0.05$, Figure 9C), compared with control cells. The change pattern of FFA concentration in SLC27A1 knockdown was discrepant with that in SLC27A1 overexpression, suggesting that SLC27A1 may not be primary fatty acid transporter but function on lipid metabolism in QM-7 cell.

We also assessed SLC27A4, ACSL1, GOT2, and CD36 mRNA levels in SLC27A1-1220-transfected cells compared with control NC-transfected cells by quantitative real-time PCR (Figure 9D). SLC27A1 knockdown resulted in the down-regulated for SLC27A4 $(P<0.05)$, but no change was observed for ACSL1, GOT2 and CD36.

As well, we assessed the mRNA levels of PPARs and DEGs involved in the PPAR signaling pathway in SLC27A1-1220transfected cells compared with control NC-transfected cells by quantitative real-time PCR (Figure 9E). SLC27A1 knockdown resulted in the down-regulated for $C P T 1 A(P<0.01)$, and no changes were observed for other genes.

\section{DISCUSSION}

\section{The Higher IMF Content Is an Important Factor for the WC Chicken Excellent Meat Quality}

IMF content is positively correlated with flavor, tenderness, and juiciness (Fernandez et al., 1999b; Chartrin et al., 2006; Gao and Zhao, 2009; Cannata et al., 2010; Hocquette et al., 2010; Madeira et al., 2013). In pigs, increases in IMF content are accompanied by the increase in sensory tenderness $(P=0.001)$ and sensory 


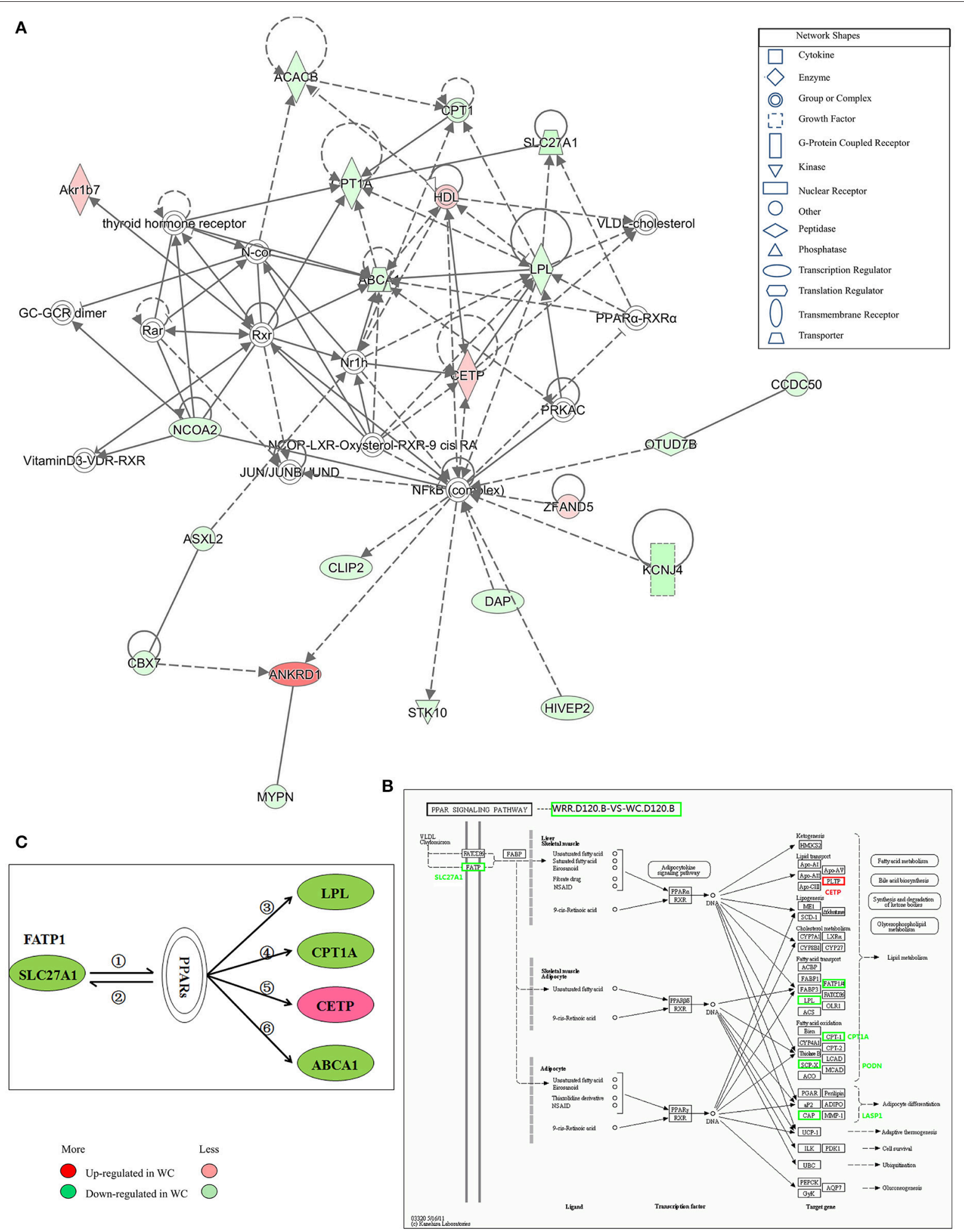

FIGURE 7 | Gene interaction network related to lipid metabolism of DEGs between WC and WRR chickens. (A) Functional gene interaction networks was identified by Ingenuity Pathway Analysis (IPA $\left.{ }^{\circledR}\right)$ software. This network shows direct gene interactions mainly in WRR.D120.B-VS-WC.D120.B related to lipid metabolism, molecular transport, small molecule biochemistry. (B) DEGs SLC27A1, LPL, CPT1A, CETP in WRR.D120.B-VS-WC.D120.B involved in PPAR signaling pathway. (C) Proposed network for SLC27A1 to regulate chicken lipid metabolism based on GO annotation, KEGG pathway and Ingenuity Pathway Analysis (IPA ${ }^{\circledR}$ ). (1) SLC27A1 


\section{FIGURE 7 | Continued}

overexpression increases fatty acids afflux, which offers ligands (Forman et al., 1995) for binding and activating PPARs; (2) expression of FATP genes (SLC27A1) involves both PPAR $\alpha$ and $-\gamma$ (Motojima et al., 1998); (3) PPAR control triglyceride metabolism by transcriptional control the expression of $L P L$ (Auwerx et al., 1996); (4) Though binding to PPAR responsive element in CPT1A, PPAR promotes fatty acid oxidation (Mascaro et al., 1998; Song et al., 2010); (5) PPAR activation may inhibit plasma CETP activity (Li and Chiang, 2009); (6) PPARs and LXRs are involved in the regulation of $A B C A 1$ expression (Chinetti et al., 2001). Genes colored in red are up-regulated expression in WC chickens, while genes colored in green are down-regulated expression in WC chickens. Color intensity correlates to the size of the fold change.

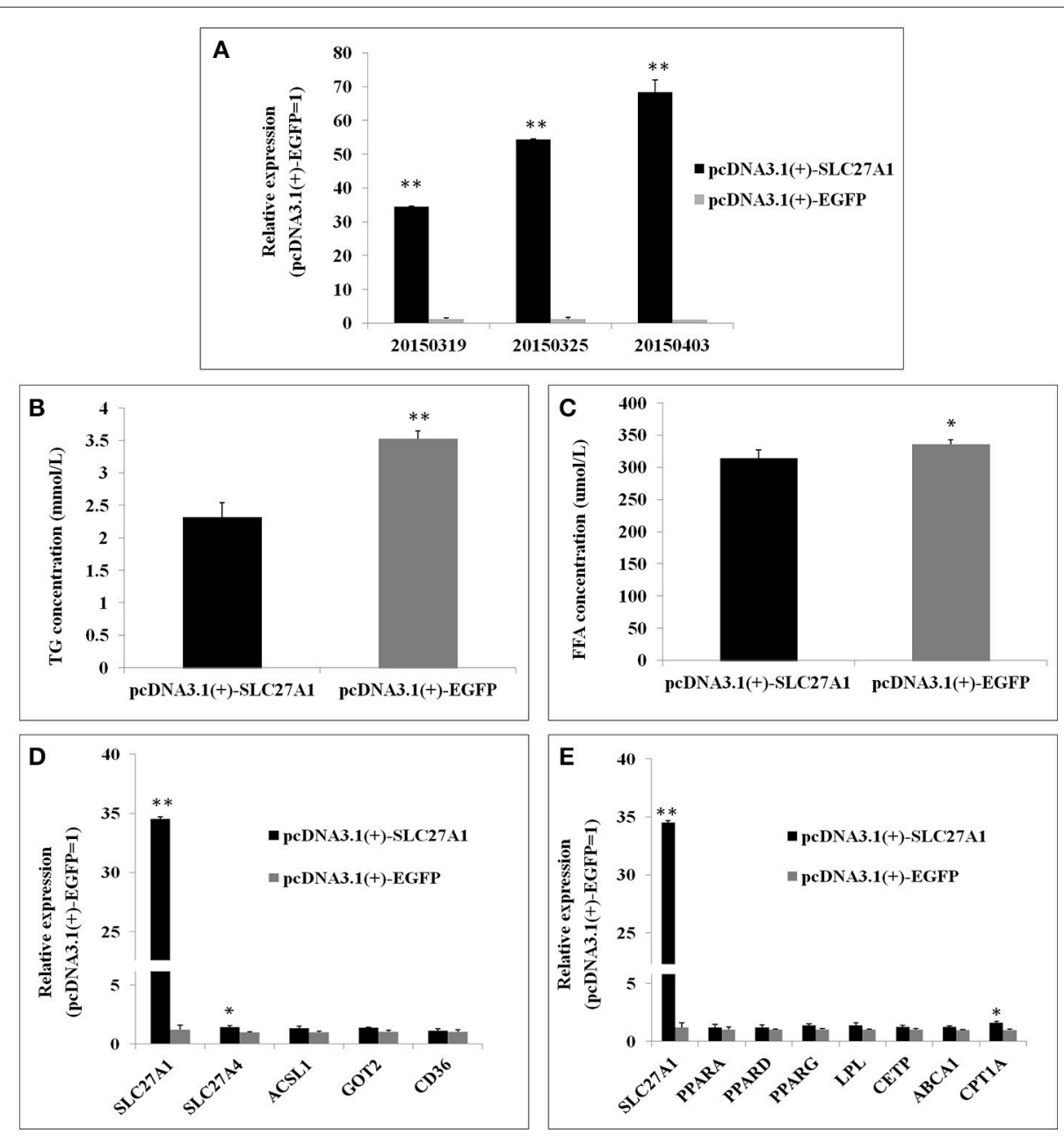

FIGURE 8 | Effect of SLC27A1 overexpression on lipid metabolism. (A) SLC27A1 overexpression efficiency. (B) Palmitate incorporation into TGs. Data are the mean \pm S.E.M of three experiments performed in triplicate. (C) Palmitic acid uptake. Data are the mean \pm S.E.M of three experiments performed in triplicate. (D) Synergy or compensation effect exist among different fatty acid transports. The data presented are representative of three independent experiments; $n=3$, mean \pm S.E.M. (E) The regulative mechanism of lipid metabolism for SLC27A1. The data presented are representative of three independent experiments; $n=3$, mean \pm S.E.M. ${ }^{*}<<$ 0.05, pcDNA3.1(+)-SLC27A1 vs. pcDNA3.1(+)-EGFP; ${ }^{\star \star} P<0.01$, pcDNA3.1(+)-SLC27A1 vs. pcDNA3.1(+)-EGFP.

juiciness scores $(P=0.017$; Cannata et al., 2010). In ducks, increasing lipid levels in breast muscle promoted tenderness and flavor, with correlation coefficients of 0.43 and 0.28 , respectively (Chartrin et al., 2006). IMF affects meat quality positively mainly for two reasons. First, the oxidation of IMF can dissolve the muscle fiber bundle, thus improving the tenderness and juiciness of muscles. Second, IMF contains plenty of phospholipids, the degradation of phospholipids in heating produces various kinds of volatile aromatic compounds, thus improving the flavor of muscles. The present study showed that the IMF content of WC chickens were significantly higher than that of WRR chickens at two ages (Table 1), suggesting that the higher IMF content resulted in better meat quality of WC chickens.

\section{Lower Lipid Catabolism Exists in WC Chicken}

In the present study, we compared and analyzed the breast transcriptional profiles of WC chickens and WRR chickens of 


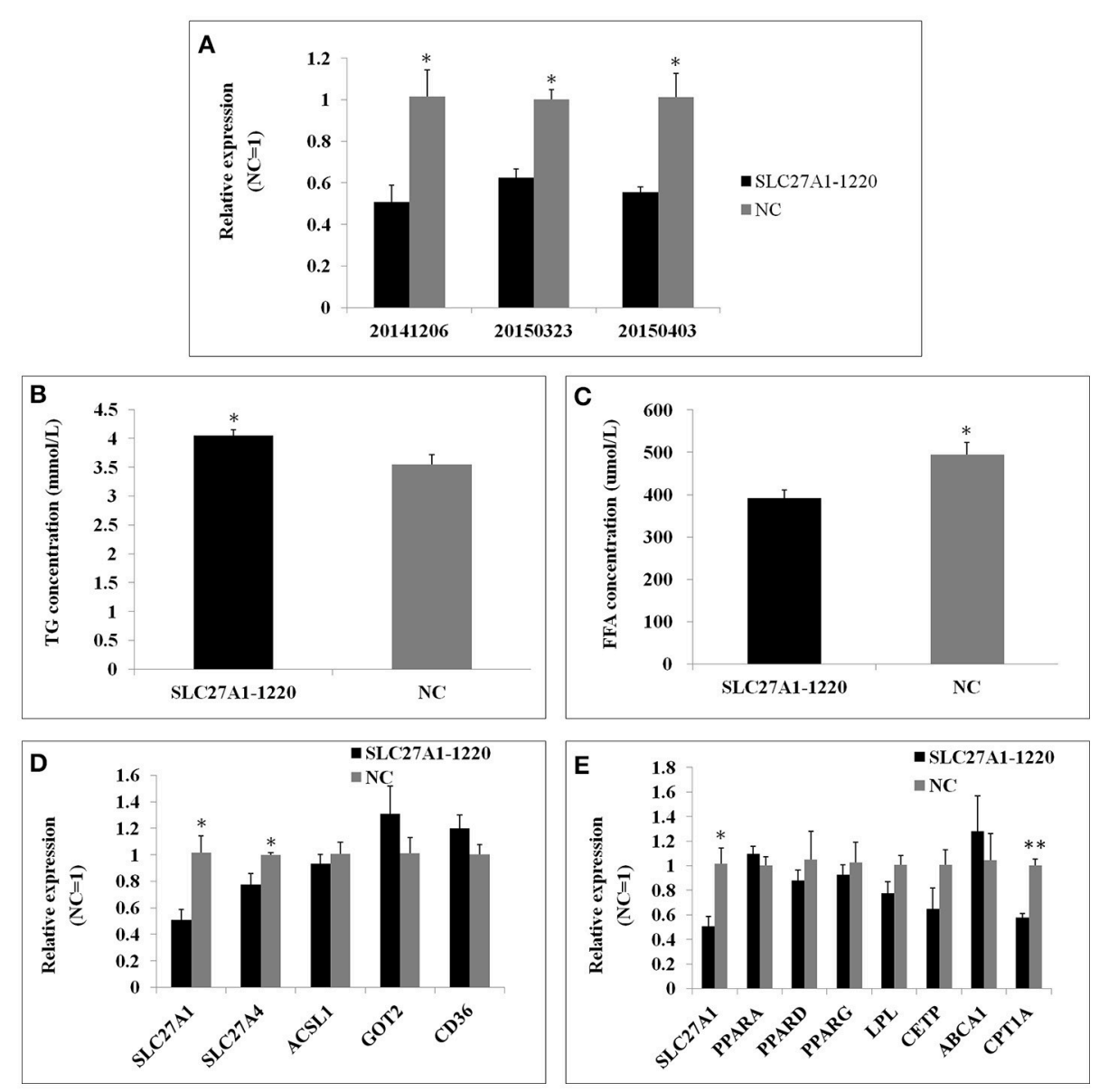

FIGURE 9 | Effect of SLC27A1 knockdown on lipid metabolism. (A) SLC27A1 interference efficiency. (B) Palmitate incorporation into TGs. Data are the mean \pm S.E.M of three experiments performed in triplicate. (C) Palmitic acid uptake. Data are the mean \pm S.E.M of three experiments performed in triplicate. (D) Synergy or compensation effect exist among different fatty acid transports. The data presented are representative of three independent experiments; $n=3$, mean \pm S.E.M. (E) The regulative mechanism of lipid metabolism for SLC27A1. The data presented are representative of three independent experiments; $n=3$, mean \pm S.E.M. ${ }^{\star} P<$ 0.05, SLC27A1-1220 vs. NC; ${ }^{* *} P<0.01$, SLC27A1-1220 vs. NC.

distinct genetic background, and a lot of DEGs between breeds and within breeds affecting IMF deposition were identified. These DEGs such as $A B C A 1, C P T 1 A, L P L$, and SLC27A1 were mostly down-regulated in WC chickens (Supplementary Table 3).

$A B C A 1$ (ATP-binding cassette transporter A1) functions as a cholesteral efflux pump in the cellular lipid removal pathway (Santamarina-Fojo et al., 2001; Alder-Baerens et al., 2005). $A B C A 1$ deficiency reduces lipid efflux, and results in lipid accumulation in the central nervous system (Hirsch-Reinshagen et al., 2004). CPT1A (Carnitine palmitoyl transferase I, liver) is a rate-limiting enzyme of mitochondrial fatty acid beta-oxidation (McGarry and Brown, 1997; Zammit, 2008; Akkaoui et al., 2009), and plays a prominent role in triglyceride metabolism. Overexpression of the CPT1A enhanced fatty acid oxidation in hepatocytes, $\beta$-Cells and muscle cells (Perdomo et al., 2004; Herrero et al., 2005; Stefanovic-Racic et al., 2008; Akkaoui et al., 2009), and decreased lipid accumulation (Stefanovic-Racic et al., 2008; Akkaoui et al., 2009). CETP (Cholesteryl ester transfer protein) is involved in the transfer of neutral lipids, including cholesteryl ester and triglyceride, among lipoprotein particles.
Overexpressed CETP in SW872 cells and mice both reduced TG accumulation (Izem et al., 2015; Palmisano et al., 2016), while in chickens CETP was positively correlated with phospholipid accumulation (Cui et al., 2012). LPL (Lipoprotein lipase) has the dual functions of triglyceride hydrolase and lipoprotein uptake (Gotoda et al., 1989; Goldberg, 1996). LPL is an important candidate gene for chicken lipid metabolism, and the mRNA level and enzymatic activity of $L P L$ was negatively correlated with IMF contents (Claire et al., 2013; Zhang X. D. et al., 2015). SLC27A1 is involved in translocation of long-chain fatty acids (LFCAs) across the plasma membrane and subsequently lipid metabolism in skeletal muscle (García-Martínez et al., 2005; Sebastian et al., 2009; Holloway et al., 2011; Guitart et al., 2014), heart (Chiu et al., 2005), 3T3-L1 cell (Lobo et al., 2007), and 293 cell (Hatch et al., 2002).

Overexpression of the SLC27A1 increased rate of fatty acid oxidation in heart (Chiu et al., 2005) and skeletal muscle (Nickerson et al., 2009; Sebastian et al., 2009; Holloway et al., 2011; Guitart et al., 2014), reduced TG accumulation in skeletal muscle (Guitart et al., 2014). 
Moreover, ABCA1, CPT1A, LPL, and SLC27A1 were all involved in the PPAR signaling pathway (Figure 7B), a wellknown pathway affecting lipid metabolism (Kokta et al., 2004; Du et al., 2010), and formed a IPA ${ }^{\circledR}$ network related to lipid metabolism, molecular transport, small molecule biochemistry (Figure 5A), implying that these genes may be key genes affecting chicken IMF deposition and their down-regulated expression means that a lower lipid catabolism exists in WC chicken.

\section{SLC27A1 Negatively Regulated Lipid Accumulation of Chicken via CPT1A}

Our RNA-seq data revealed that SLC27A1 was lower expressed in WC.D120.B and WRR.D180.B compared with in WRR.D120.B, while the IMF content of WC.D120.B and WRR.D180.B were higher than that of WRR.D120.B (Table 1). In other words, SLC27A1 is generally expressed lower in muscles with higher IMF contents. Our findings in cell experiments further confirmed these results. Overexpression of SCL27A1 in QM-7 cells caused the decrease in the cellular TG content (Figure 8B), while knockdown of SLC27A1 with RNAi resulted in the increase in the cellular TG content (Figure 9B). The reduced intramuscular TG was also observed in mouse skeletal muscle overexpressed SLC27A1 (Guitart et al., 2014). Overall, SLC27A1 is negatively correlated with the lipid accumulation.

Previous studies have shown that overexpressed SLC27A1 in the skeletal muscle promoted fatty acid oxidation (Holloway et al., 2011; Guitart et al., 2014). Overexpression of SLC27A1 increased the expression of CPT1A (Figure 8E), and knockdown of SLC27A1 decreased the expression of CPT1A (Figure 9E), suggesting that $S L C 27 A 1$ may regulate the expression of CPT1A in some way. PPARs are known to be pivotal transcription factors of genes involved in lipid metabolism (Lemberger et al., 1996). Their binding to PPAR responsive element localized in the $5^{\prime}$-flanking region (Mascaro et al., 1998) and the second intron (Song et al., 2010) both increased CPT1A expression. As fatty acids and their derivatives are ligands for PPARs (Forman et al., 1995), it is possible that SLC27A1 overexpression increases fatty acids afflux and activation, which offers ligands for binding and activating PPARs, in turn activating the PPARs-dependent gene transcription, such as CPT1A, a rate-limiting enzyme of mitochondrial fatty acid oxidation (McGarry and Brown, 1997; Zammit, 2008; Akkaoui et al., 2009). In addition, cellular FFA change patterns were discrepant in SLC27A1 overexpression (Figure 8C) and knockdown (Figure 9C), indicating that SLC27A1 plays a supplementary role in fatty acid transport, similar in rat skeletal muscle (Nickerson et al., 2009). Therefore, SLC27A1 involves in fatty acids oxidation through collaboration with CPT1A (Sebastian et al., 2009), similar to FAT/CD36 (Campbell et al., 2004; Schenk and Horowitz, 2006), but not for its transport activity across mitochondrial membrane.

Several fatty acid transporters, fatty acid translocase (FAT/CD36; Campbell et al., 2004; Schenk and Horowitz, 2006; Smith et al., 2011), plasm membrane fatty acid binding protein (FABPpm/GOT2; Clarke et al., 2004), long chain Acyl-CoA synthetase (ACSLs; Ellis et al., 2011), and fatty acid transporters (FATPs; Stahl, 2004; Kazantzis and Stahl, 2012), have been identified contributing to fatty acids uptake and oxidation. Some transporters may cooperate concertedly in fatty acids uptake, such as FABPpm and CD36 in heart and muscle (Chabowski et al., 2007), CD36 and ACSL1 in MDCK cell (Schneider et al., 2014), and ACSL1 and FATP1 in adipocytes (Richards et al., 2006). Both FATP1 and FATP4 belong to the FATP family, and their amino acid identity is $60.3 \%$ (Herrmann et al., 2001). FATP1 may involve in fatty acid uptake by hormonal regulation, while FATP4 may mediate fatty acid uptake on the basal level (Stahl et al., 2002). These fatty acid transporters are coexpressed in skeletal muscle for unknown reasons, and their functional impact with each other remains unknown. In this study, overexpression or knockdown of the SLC27A1 could not change the expression of the ACSL1, GOT2, and CD36 (Figures 8D, 9D). These findings indicate that different fatty acid transporters have distinct transcription regulatory mechanism, while SLC27A4, for its high homology with SLC27A1, was regulated similar to SLC27A1.

In conclusion, the present study showed that a higher IMF content resulted in a better meat quality of WC chickens. Lower lipid metabolism exists in WC chickens, the higher IMF deposition in WC chickens may be due to its lower fatty acid oxidation, and lower expression of SLC27A1 down-regulated the fatty acid oxidation by collaboration with $C P T 1 A$. Moreover, these findings also indicate that reduced lipid catabolism, rather than increased lipid anabolism, contributes to chicken IMF deposition.

\section{AUTHOR CONTRIBUTIONS}

FQ, LX, JM, WL, LZ, ZC, and SC performed experiments. $\mathrm{FQ}$, LX contributed to the data analysis. FQ and $\mathrm{XZ}$ wrote the manuscript. FQ, LX, QN, ZL, and XZ contributed to the experimental design. All authors approved the final manuscript.

\section{FUNDING}

This work was supported by National Natural Science Foundation of China (31260548) and the China Agriculture Research System (CARS-42-G05).

\section{ACKNOWLEDGMENTS}

We acknowledge Dr. Xiaofei Wang (Department of Biological Sciences, Tennessee State University, Nashville, USA) for his valuable comments and suggestions on manuscript preparing. We acknowledge Longquan Wenchang Chicken Industrial co., LTD (Wenchang, Hainan, China) and Guangdong Wen's Food Group, LTD (Xinxing, Guangdong, China) for their selfless offering of WC and WRR chickens

\section{SUPPLEMENTARY MATERIAL}

The Supplementary Material for this article can be found online at: http://journal.frontiersin.org/article/10.3389/fphys. 2017.00449/full\#supplementary-material 


\section{Availability of Supporting Data}

The data discussed in this publication have been deposited in NCBI's Gene Expression Omnibus (Edgar et al., 2002)

\section{REFERENCES}

Akkaoui, M., Cohen, I., Esnous, C., Lenoir, V., Sournac, M., Girard, J., et al. (2009). Modulation of the hepatic malonyl-CoA-carnitine palmitoyltransferase 1A partnership creates a metabolic switch allowing oxidation of de novo fatty acids. Biochem. J. 420, 429-438. doi: 10.1042/BJ20081932

Alder-Baerens, N., Muller, P., Pohl, A., Korte, T., Hamon, Y., Chimini, G., et al. (2005). Headgroup-specific exposure of phospholipids in ABCA1-expressing cells. J. Biol. Chem. 280, 26321-26329. doi: 10.1074/jbc.M413993200

Altermann, E., and Klaenhammer, T. R. (2005). PathwayVoyager: pathway mapping using the Kyoto Encyclopedia of Genes and Genomes (KEGG) database. BMC Genomics 6:60. doi: 10.1186/1471-2164-6-60

Ashburner, M., Ball, C. A., Blake, J. A., Botstein, D., Butler, H., Cherry, J. M., et al. (2000). Gene ontology: tool for the unification of biology. The Gene Ontology Consortium. Nat. Genet. 25, 25-29. doi: 10.1038/75556

Auwerx, J., Schoonjans, K., Fruchart, J. C., and Staels, B. (1996). Transcriptional control of triglyceride metabolism: fibrates and fatty acids change the expression of the LPL and apo C-III genes by activating the nuclear receptor PPAR. Atherosclerosis 124(Suppl.), S29-S37. doi: 10.1016/0021-9150(96)05854-6

Bourneuf, E., Herault, F., Chicault, C., Carre, W., Assaf, S., Monnier, A., et al. (2006). Microarray analysis of differential gene expression in the liver of lean and fat chickens. Gene 372, 162-170. doi: 10.1016/j.gene.2005.12.028

Calkins, C. R., and Hodgen, J. M. (2007). A fresh look at meat flavor. Meat Sci. 77, 63-80. doi: 10.1016/j.meatsci.2007.04.016

Campbell, S. E., Tandon, N. N., Woldegiorgis, G., Luiken, J. J., Glatz, J. F., and Bonen, A. (2004). A novel function for fatty acid translocase (FAT)/CD36: involvement in long chain fatty acid transfer into the mitochondria. J. Biol. Chem. 279, 36235-36241. doi: 10.1074/jbc.M400566200

Cannata, S., Engle, T. E., Moeller, S. J., Zerby, H. N., Radunz, A. E., Green, M. D., et al. (2010). Effect of visual marbling on sensory properties and quality traits of pork loin. Meat Sci. 85, 428-434. doi: 10.1016/j.meatsci.2010.02.011

Chabowski, A., Gorski, J., Luiken, J. J., Glatz, J. F., and Bonen, A. (2007). Evidence for concerted action of FAT/CD36 and FABPpm to increase fatty acid transport across the plasma membrane. Prostaglandins Leukot. Essent. Fatty Acids 77, 345-353. doi: 10.1016/j.plefa.2007.10.017

Chartrin, P., Meteau, K., Juin, H., Bernadet, M. D., Guy, G., Larzul, C., et al. (2006). Effects of intramuscular fat levels on sensory characteristics of duck breast meat. Poult. Sci. 85, 914-922. doi: 10.1093/ps/85.5.914

Chinetti, G., Lestavel, S., Bocher, V., Remaley, A. T., Neve, B., Torra, I. P., et al. (2001). PPAR-alpha and PPAR-gamma activators induce cholesterol removal from human macrophage foam cells through stimulation of the ABCA1 pathway. Nat. Med. 7, 53-58. doi: 10.1038/83348

Chiu, H.-C., Kovacs, A., Blanton, R. M., Han, X., Courtois, M., Weinheimer, C. J., et al. (2005). Transgenic expression of fatty acid transport protein 1 in the heart causes lipotoxic cardiomyopathy. Circ. Res. 96, 225-233. doi: 10.1161/01.RES. 0000154079.20681.B9

Claire, D. H., Paul, W., Shen, X., Jia, X., Zhang, R., Sun, L., et al. (2013). Identification and characterization of genes that control fat deposition in chickens. J. Anim. Sci. Biotechnol. 4:43. doi: 10.1186/2049-1891-4-43

Clarke, D. C., Miskovic, D., Han, X. X., Calles-Escandon, J., Glatz, J. F., Luiken, J. J., et al. (2004). Overexpression of membrane-associated fatty acid binding protein (FABPpm) in vivo increases fatty acid sarcolemmal transport and metabolism. Physiol. Genomics 17, 31-37. doi: 10.1152/physiolgenomics. 0019 0.2003

Cui, H. X., Liu, R. R., Zhao, G. P., Zheng, M. Q., Chen, J. L., and Wen, J. (2012). Identification of differentially expressed genes and pathways for intramuscular fat deposition in pectoralis major tissues of fast-and slow-growing chickens. BMC Genomics 13:213. doi: 10.1186/1471-2164-13-213

D’Andre, H. C., Yan, W., Wallace, P., Nie, Q., Luo, C., Li, H., et al. (2010). Effects of the thyroid hormone responsive spot 14alpha gene on chicken and are accessible through GEO Series accession number GSE86920 (https://www.ncbi.nlm.nih.gov/geo/query/acc.cgi? acc $=$ GSE86920). growth and fat traits. Poult. Sci. 89, 1981-1991. doi: 10.3382/ps.200900582

Dransfield, E., and Sosnicki, A. A. (1999). Relationship between muscle growth and poultry meat quality. Poult. Sci. 78, 743-746. doi: 10.1093/ps/78. 5.743

Du, M., Yin, J., and Zhu, M. J. (2010). Cellular signaling pathways regulating the initial stage of adipogenesis and marbling of skeletal muscle. Meat Sci. 86, 103-109. doi: 10.1016/j.meatsci.2010.04.027

Edgar, R., Domrachev, M., and Lash, A. E. (2002). Gene Expression Omnibus: NCBI gene expression and hybridization array data repository. Nucleic Acids Res. 30, 207-210. doi: 10.1093/nar/30.1.207

Ellis, J. M., Mentock, S. M., Depetrillo, M. A., Koves, T. R., Sen, S., Watkins, S. M., et al. (2011). Mouse cardiac acyl coenzyme a synthetase 1 deficiency impairs Fatty Acid oxidation and induces cardiac hypertrophy. Mol. Cell. Biol. 31, 1252-1262. doi: 10.1128/MCB.01085-10

Fernandez, X., Monin, G., Talmant, A., Mourot, J., and Lebret, B. (1999a). Influence of intramuscular fat content on the quality of pig meat - 2 . Consumer acceptability of $m$. longissimus lumborum. Meat Sci. 53, 67-72. doi: 10.1016/S0309-1740(99)00038-8

Fernandez, X., Monin, G., Talmant, A., Mourot, J., and Lebret, B. (1999b). Influence of intramuscular fat content on the quality of pig meat - 1 . Composition of the lipid fraction and sensory characteristics of $m$. longissimus lumborum. Meat Sci. 53, 59-65. doi: 10.1016/S0309-1740(99)00037-6

Forman, B. M., Tontonoz, P., Chen, J., Brun, R. P., Spiegelman, B. M., and Evans, R. M. (1995). 15-Deoxy-delta 12, 14-prostaglandin J2 is a ligand for the adipocyte determination factor PPAR gamma. Cell 83, 803-812. doi: 10.1016/0092-8674(95)90193-0

Gao, S. Z., and Zhao, S. M. (2009). Physiology, affecting factors and strategies for control of pig meat intramuscular fat. Recent Pat. Food Nutr. Agric. 1, 59-74. doi: 10.2174/2212798410901010059

García-Martínez, C., Marotta, M., Moore-Carrasco, R., Guitart, M., Camps, M., Busquets, S., et al. (2005). Impact on fatty acid metabolism and differential localization of FATP1 and FAT/CD36 proteins delivered in cultured human muscle cells. Am. J. Physiol. Cell Physiol. 288, C1264-C1272. doi: 10.1152/ ajpcell.00271.2004

Glatz, J. F., Luiken, J. J., and Bonen, A. (2010). Membrane fatty acid transporters as regulators of lipid metabolism: implications for metabolic disease. Physiol. Rev. 90, 367-417. doi: 10.1152/physrev.00003.2009

Goldberg, I. J. (1996). Lipoprotein lipase and lipolysis: central roles in lipoprotein metabolism and atherogenesis. J. Lipid Res. 37, 693-707.

Gotoda, T., Senda, M., Gamou, T., Furuichi, Y., and Oka, K. (1989). Nucleotide sequence of human cDNA coding for a lipoprotein lipase (LPL) cloned from placental cDNA library. Nucleic Acids Res. 17:2351. doi: 10.1093/nar/17.6.2351

Griffin, H. D., Butterwith, S. C., and Goddard, C. (1987). Contribution of lipoprotein lipase to differences in fatness between broiler and layerstrain chickens. Br. Poult. Sci. 28, 197-206. doi: 10.1080/000716687084 16953

Guitart, M., Osorio-Conles, O., Pentinat, T., Cebria, J., Garcia-Villoria, J., Sala, D., et al. (2014). Fatty acid transport protein 1 (FATP1) localizes in mitochondria in mouse skeletal muscle and regulates lipid and ketone body disposal. PLoS ONE 9:e98109. doi: 10.1371/journal.pone.0098109

Hatch, G. M., Smith, A. J., Xu, F. Y., Hall, A. M., and Bernlohr, D. A. (2002). FATP1 channels exogenous FA into 1,2,3-triacyl-sn-glycerol and downregulates sphingomyelin and cholesterol metabolism in growing 293 cells. J. Lipid Res. 43, 1380-1389. doi: 10.1194/jlr.M200130-JLR200

Herrero, L., Rubi, B., Sebastian, D., Serra, D., Asins, G., Maechler, P., et al. (2005). Alteration of the malonyl-CoA/carnitine palmitoyltransferase I interaction in the beta-cell impairs glucose-induced insulin secretion. Diabetes 54, 462-471. doi: $10.2337 /$ diabetes.54.2.462

Herrmann, T., Buchkremer, F., Gosch, I., Hall, A. M., Bernlohr, D. A., and Stremmel, W. (2001). Mouse fatty acid transport protein 4 (FATP4): 
characterization of the gene and functional assessment as a very long chain acyl-CoA synthetase. Gene 270, 31-40. doi: 10.1016/S0378-1119(01)00489-9

Hirsch-Reinshagen, V., Zhou, S., Burgess, B. L., Bernier, L., McIsaac, S. A., Chan, J. Y., et al. (2004). Deficiency of ABCA1 impairs apolipoprotein E metabolism in brain. J. Biol. Chem. 279, 41197-41207. doi: 10.1074/jbc.M407962200

Hocquette, J. F., Gondret, F., Baeza, E., Medale, F., Jurie, C., and Pethick, D. W. (2010). Intramuscular fat content in meat-producing animals: development, genetic and nutritional control, and identification of putative markers. Animal 4, 303-319. doi: 10.1017/S1751731109991091

Holloway, G. P., Chou, C. J., Lally, J., Stellingwerff, T., Maher, A. C., Gavrilova, O., et al. (2011). Increasing skeletal muscle fatty acid transport protein 1 (FATP1) targets fatty acids to oxidation and does not predispose mice to diet-induced insulin resistance. Diabetologia 54, 1457-1467. doi: 10.1007/s00125-0112114-8

Izem, L., Greene, D. J., Bialkowska, K., and Morton, R. E. (2015). Overexpression of full-length cholesteryl ester transfer protein in SW872 cells reduces lipid accumulation. J. Lipid Res. 56, 515-525. doi: 10.1194/jlr.M053678

Jennen, D. G., Vereijken, A. L., Bovenhuis, H., Crooijmans, R. M., van der Poel, J. J., and Groenen, M. A. (2005). Confirmation of quantitative trait loci affecting fatness in chickens. Genet Sel Evol. 37, 215-228. doi: 10.1186/1297-9686-37-3-215

Jeong, J., Kwon, E. G., Im, S. K., Seo, K. S., and Baik, M. (2012). Expression of fat deposition and fat removal genes is associated with intramuscular fat content in longissimus dorsi muscle of Korean cattle steers. J. Anim. Sci. 90, 2044-2053. doi: $10.2527 /$ jas.2011-4753

Jia, X., Nie, Q., Lamont, S. J., and Zhang, X. (2012). Variation in sequence and expression of the avian FTO, and association with glucose metabolism, body weight, fatness and body composition in chickens. Int. J. Obes. 36, 1054-1061. doi: 10.1038/ijo.2011.221

Kanehisa, M., Araki, M., Goto, S., Hattori, M., Hirakawa, M., Itoh, M., et al. (2008). KEGG for linking genomes to life and the environment. Nucleic Acids Res. 36, D480-D484. doi: 10.1093/nar/gkm882

Kazantzis, M., and Stahl, A. (2012). Fatty acid transport proteins, implications in physiology and disease. Biochim. Biophys. Acta 1821, 852-857. doi: 10.1016/j.bbalip.2011.09.010

Kokta, T. A., Dodson, M. V., Gertler, A., and Hill, R. A. (2004). Intercellular signaling between adipose tissue and muscle tissue. Domest. Anim. Endocrinol. 27, 303-331. doi: 10.1016/j.domaniend.2004.05.004

Lemberger, T., Desvergne, B., and Wahli, W. (1996). Peroxisome proliferatoractivated receptors: a nuclear receptor signaling pathway in lipid physiology. Annu. Rev. Cell Dev. Biol. 12, 335-363. doi: 10.1146/annurev.cellbio.12.1.335

Leveille, G. A. (1969). In vitro hepatic lipogenesis in the hen and chick. Comp. Biochem. Physiol. 28, 431-435. doi: 10.1016/0010-406X(69)91357-7

Li, R., Yu, C., Li, Y., Lam, T. W., Yiu, S. M., Kristiansen, K., et al. (2009). SOAP2: an improved ultrafast tool for short read alignment. Bioinformatics 25, 1966-1967. doi: 10.1093/bioinformatics/btp336

Li, T., and Chiang, J. Y. (2009). Regulation of bile acid and cholesterol metabolism by PPARs. PPAR Res. 2009:501739. doi: 10.1155/2009/501739

Li, T., Xu, D., Zuo, B., Lei, M., Xiong, Y., Chen, H., et al. (2013). Ectopic overexpression of porcine DGAT1 increases intramuscular fat content in mouse skeletal muscle. Transgenic Res. 22, 187-194. doi: 10.1007/s11248-012-9633-Z

Liu, R., Sun, Y., Zhao, G., Wang, F., Wu, D., Zheng, M., et al. (2013). Genome-wide association study identifies Loci and candidate genes for body composition and meat quality traits in Beijing-You chickens. PLoS ONE 8:e61172. doi: 10.1371/journal.pone.0061172

Lobo, S., Wiczer, B. M., Smith, A. J., Hall, A. M., and Bernlohr, D. A. (2007). Fatty acid metabolism in adipocytes: functional analysis of fatty acid transport proteins 1 and 4. J. Lipid Res. 48, 609-620. doi: 10.1194/jlr.M600441-JLR200

Madeira, M. S., Costa, P., Alfaia, C. M., Lopes, P. A., Bessa, R. J., Lemos, J. P., et al. (2013). The increased intramuscular fat promoted by dietary lysine restriction in lean but not in fatty pig genotypes improves pork sensory attributes. J. Anim. Sci. 91, 3177-3187. doi: 10.2527/jas.2012-5424

Mascaro, C., Acosta, E., Ortiz, J. A., Marrero, P. F., Hegardt, F. G., and Haro, D. (1998). Control of human muscle-type carnitine palmitoyltransferase I gene transcription by peroxisome proliferator-activated receptor. J. Biol. Chem. 273, 8560-8563. doi: 10.1074/jbc.273.15.8560

McGarry, J. D., and Brown, N. F. (1997). The mitochondrial carnitine palmitoyltransferase system. From concept to molecular analysis.
Eur. J. Biochem. 244, 1-14. doi: 10.1111/j.1432-1033.1997.0 0001.x

Motojima, K., Passilly, P., Peters, J. M., Gonzalez, F. J., and Latruffe, N. (1998). Expression of putative fatty acid transporter genes are regulated by peroxisome proliferator-activated receptor alpha and gamma activators in a tissue- and inducer-specific manner. J. Biol. Chem. 273, 16710-16714. doi: $10.1074 /$ jbc.273.27.16710

Nassar, M. K., Goraga, Z. S., and Brockmann, G. A. (2013). Quantitative trait loci segregating in crosses between New Hampshire and White Leghorn chicken lines: III. Fat deposition and intramuscular fat content. Anim. Genet. 44, 62-68. doi: 10.1111/j.1365-2052.2012.02365.x

Nickerson, J. G., Alkhateeb, H., Benton, C. R., Lally, J., Nickerson, J., Han, X. X., et al. (2009). Greater transport efficiencies of the membrane fatty acid transporters FAT/CD36 and FATP4 compared with FABPpm and FATP1 and differential effects on fatty acid esterification and oxidation in rat skeletal muscle. J. Biol. Chem. 284, 16522-16530. doi: 10.1074/jbc.M109.004788

Ozaki, K., and Leonard, W. J. (2002). Cytokine and cytokine receptor pleiotropy and redundancy. J. Biol. Chem. 277, 29355-29358. doi: 10.1074/jbc.R200003200

Palmisano, B. T., Le, T. D., Zhu, L., Lee, Y. K., and Stafford, J. M. (2016). Cholesteryl ester transfer protein alters liver and plasma triglyceride metabolism through two liver networks in female mice. J. Lipid Res. 57, 1541-1551. doi: 10.1194/jlr.m069013

Perdomo, G., Commerford, S. R., Richard, A. M., Adams, S. H., Corkey, B. E., O’Doherty, R. M., et al. (2004). Increased beta-oxidation in muscle cells enhances insulin-stimulated glucose metabolism and protects against fatty acid-induced insulin resistance despite intramyocellular lipid accumulation. J. Biol. Chem. 279, 27177-27186. doi: 10.1074/jbc.M403566200

Petit, V., and Thiery, J. P. (2000). Focal adhesions: structure and dynamics. Biol. Cell 92, 477-494. doi: 10.1016/S0248-4900(00)01101-1

Petracci, M., and Cavani, C. (2012). Muscle growth and poultry meat quality issues. Nutrients 4, 1-12. doi: 10.3390/nu4010001

Pollard, T. D. (2003). The cytoskeleton, cellular motility and the reductionist agenda. Nature 422, 741-745. doi: 10.1038/nature01598

Richards, M. R., Harp, J. D., Ory, D. S., and Schaffer, J. E. (2006). Fatty acid transport protein 1 and long-chain acyl coenzyme A synthetase 1 interact in adipocytes. J. Lipid Res. 47, 665-672. doi: 10.1194/jlr.M500514-JLR200

Rollin, X., Medale, F., Gutieres, S., Blanc, D., and Kaushik, S. J. (2003). Short- and long-term nutritional modulation of acetyl-CoA carboxylase activity in selected tissues of rainbow trout (Oncorhynchus mykiss). Br. J. Nutr. 89, 803-810. doi: 10.1079/BJN2003844

Santamarina-Fojo, S., Remaley, A. T., Neufeld, E. B., and Brewer, H. J. (2001). Regulation and intracellular trafficking of the ABCA1 transporter. J. Lipid Res. 42, 1339-1345.

Schenk, S., and Horowitz, J. F. (2006). Coimmunoprecipitation of FAT/CD36 and CPT I in skeletal muscle increases proportionally with fat oxidation after endurance exercise training. Am. J. Physiol. Endocrinol. Metab. 291, E254-E260. doi: 10.1152/ajpendo.00051.2006

Schneider, H., Staudacher, S., Poppelreuther, M., Stremmel, W., Ehehalt, R., and Füllekrug, J. (2014). Protein mediated fatty acid uptake: Synergy between CD36/FAT-facilitated transport and acyl-CoA synthetase-driven metabolism. Arch. Biochem. Biophys. 546, 8-18. doi: 10.1016/j.abb.2014. 01.025

Schwenk, R. W., Holloway, G. P., Luiken, J. J., Bonen, A., and Glatz, J. F. (2010). Fatty acid transport across the cell membrane: regulation by fatty acid transporters. Prostaglandins Leukot. Essent. Fatty Acids 82, 149-154. doi: 10.1016/j.plefa.2010.02.029

Sebastian, D., Guitart, M., Garcia-Martinez, C., Mauvezin, C., Orellana-Gavalda, J. M., Serra, D., et al. (2009). Novel role of FATP1 in mitochondrial fatty acid oxidation in skeletal muscle cells. J. Lipid Res. 50, 1789-1799. doi: 10.1194/jlr.M800535JLR200

Serao, N. V., Veroneze, R., Ribeiro, A. M., Verardo, L. L., Braccini, N. J., Gasparino, E., et al. (2011). Candidate gene expression and intramuscular fat content in pigs. J. Anim. Breed. Genet. 128, 28-34. doi: 10.1111/j.1439-0388.2010. 00887.x

Shi, Y., and Massague, J. (2003). Mechanisms of TGF-beta signaling from cell membrane to the nucleus. Cell 113, 685-700. doi: 10.1016/S0092-8674(03)00432-X 
Smith, B. K., Jain, S. S., Rimbaud, S., Dam, A., Quadrilatero, J., Ventura-Clapier, R., et al. (2011). FAT/CD36 is located on the outer mitochondrial membrane, upstream of long-chain acyl-CoA synthetase, and regulates palmitate oxidation. Biochem. J. 437, 125-134. doi: 10.1042/BJ20101861

Song, S., Attia, R. R., Connaughton, S., Niesen, M. I., Ness, G. C., Elam, M. B., et al. (2010). Peroxisome proliferator activated receptor alpha (PPARalpha) and PPAR gamma coactivator (PGC-1alpha) induce carnitine palmitoyltransferase IA (CPT-1A) via independent gene elements. Mol. Cell. Endocrinol. 325, 54-63. doi: 10.1016/j.mce.2010.05.019

Stahl, A. (2004). A current review of fatty acid transport proteins (SLC27). Pflugers Arch. 447, 722-727. doi: 10.1007/s00424-003-1106-Z

Stahl, A., Evans, J. G., Pattel, S., Hirsch, D., and Lodish, H. F. (2002). Insulin causes fatty acid transport protein translocation and enhanced fatty acid uptake in adipocytes. Dev. Cell 2, 477-488. doi: 10.1016/S1534-5807(02)00143-0

Stefanovic-Racic, M., Perdomo, G., Mantell, B. S., Sipula, I. J., Brown, N. F., and O’Doherty, R. M. (2008). A moderate increase in carnitine palmitoyltransferase la activity is sufficient to substantially reduce hepatic triglyceride levels. Am. J. Physiol. Endocrinol. Metab. 294, E969-E977. doi: 10.1152/ajpendo.004 97.2007

Sun, Y., Zhao, G., Liu, R., Zheng, M., Hu, Y., Wu, D., et al. (2013). The identification of 14 new genes for meat quality traits in chicken using a genomewide association study. BMC Genomics 14:458. doi: 10.1186/1471-2164-14-458

Vandesompele, J., De Preter, K., Pattyn, F., Poppe, B., Van Roy, N., De Paepe, A., et al. (2002). Accurate normalization of real-time quantitative RTPCR data by geometric averaging of multiple internal control genes. Genome Biol. 3:RESEARCH0034. doi: 10.1186/gb-2002-3-7-research 0034

Vernon, R. G., Barber, M. C., and Travers, M. T. (1999). Present and future studies on lipogenesis in animals and human subjects. Proc. Nutr. Soc. 58, 541-549. doi: $10.1017 /$ S0029665199000713

Wood, J. D., Enser, M., Fisher, A. V., Nute, G. R., Sheard, P. R., Richardson, R. I., et al. (2008). Fat deposition, fatty acid composition and meat quality: a review. Meat Sci. 78, 343-358. doi: 10.1016/j.meatsci.2007.07.019

Xu, Y., Huang, J., Xin, W., Chen, L., Zhao, X., Lv, Z., et al. (2014). Lipid accumulation is ahead of epithelial-to-mesenchymal transition and therapeutic intervention by acetyl-CoA carboxylase 2 silence in diabetic nephropathy. Metab. Clin. Exp. 63, 716-726. doi: 10.1016/j.metabol.2014.02.010

Ye, M. H., Chen, J. L., Zhao, G. P., Zheng, M. Q., and Wen, J. (2010). Associations of A-FABP and H-FABP markers with the content of intramuscular fat in Beijing-You chicken. Anim. Biotechnol. 21, 14-24. doi: 10.1080/10495390903328116

Young, M. D., Wakefield, M. J., Smyth, G. K., and Oshlack, A. (2010). Gene ontology analysis for RNA-seq: accounting for selection bias. Genome Biol. 11:R14. doi: 10.1186/gb-2010-11-2-r14

Zammit, V. A. (2008). Carnitine palmitoyltransferase 1: central to cell function. IUBMB Life 60, 347-354. doi: 10.1002/iub.78

Zerehdaran, S., Vereijken, A. L., van Arendonk, J. A., and van der Waaijt, E. H. (2004). Estimation of genetic parameters for fat deposition and carcass traits in broilers. Poult. Sci. 83, 521-525. doi: 10.1093/ps/83. 4.521

Zhang, T., Fan, Q. C., Wang, J. Y., Zhang, G. X., Gu, Y. P., and Tang, Y. (2015). Genome-wide association study of meat quality traits in chicken. Genet. Mol. Res. 14, 10452-10460. doi: 10.4238/2015.September.8.6

Zhang, X. D., Li, Q. H., Lou, L. F., Liu, J., Chen, X. H., Zhang, C. X., et al. (2015). High-resolution melting curve analysis of the ADSL and LPL genes and their correlation with meat quality and blood parameters in chickens. Genet. Mol. Res. 14, 2031-2040. doi: 10.4238/2015.March. 20.13

Conflict of Interest Statement: The authors declare that the research was conducted in the absence of any commercial or financial relationships that could be construed as a potential conflict of interest.

Copyright (c) 2017 Qiu, Xie, Ma, Luo, Zhang, Chao, Chen, Nie, Lin and Zhang. This is an open-access article distributed under the terms of the Creative Commons Attribution License (CC BY). The use, distribution or reproduction in other forums is permitted, provided the original author(s) or licensor are credited and that the original publication in this journal is cited, in accordance with accepted academic practice. No use, distribution or reproduction is permitted which does not comply with these terms. 